\title{
GUIDELINE
}

\section{Guidelines for the prevention, detection and management of the renal complications of COVID- 19 in Africa}

\begin{abstract}
Hesham M Elsayed ${ }^{*}$, Shoyab Wadee ${ }^{* 2}$, Mohamed S Zaki ${ }^{* 3}$, Anthony JO Were", Gloria E Ashuntantang ${ }^{5}$, Ebun L Bamgboye ${ }^{6}$, Mogamat Razeen Davids ${ }^{7}$, Mohamed H Hafez $z^{8}$, Maimouna Mahamat ${ }^{5}$, Saraladevi Naicker', Abdou Niang ${ }^{10}$, Sidy M Seck"', Charles R Swanepoel'2, Elliot KTannor ${ }^{13}$, Ahmed Twahir ${ }^{14}$, K Hubert Yao $^{15}$

"These joint first authors contributed equally to the work.

'Departments of Internal Medicine and Nephrology, Ain Shams Medical University, Cairo, Egypt; ${ }^{2}$ Wits Donald Gordon Medical Centre, University of the Witwatersrand, Johannesburg, South Africa; ${ }^{2}$ Nephrology Department, National Institute of Urology and Nephrology, Cairo, Egypt; ${ }^{4}$ East African Kidney Institute, and Department of Medicine, College of Health Sciences, University of Nairobi, Kenya; ${ }^{5}$ Department of Internal Medicine, Yaoundé General Hospital and University of Yaoundé l, Cameroon; ${ }^{\circ}$ St Nicholas Hospital, Lagos, Nigeria; ${ }^{7}$ Division of Nephrology, Stellenbosch University and Tygerberg Hospital, Cape Town, South Africa; ${ }^{8}$ Nephrology Department, Faculty of Medicine, Cairo University, Cairo, Egypt; ${ }^{9}$ Department of Internal Medicine, School of Clinical Medicine, University of the Witwatersrand, Johannesburg, South Africa; ' ${ }^{\circ}$ Department of Nephrology, Cheikh Anta Diop University, Dakar, Senegal; "Departments of Internal Medicine and Nephrology, Faculty of Health Sciences, Gaston Berger University, Saint-Louis, Senegal; ' 2 Division of Nephrology, Department of Medicine, University of Cape Town, South Africa; ' 3 Renal Unit, Department of Medicine, Komfo Anokye Teaching Hospital, Kumasi, Ghana; ${ }^{14}$ Parklands Kidney Centre and Aga Khan University Hospital, Nairobi, Kenya; ${ }^{15}$ University Hospital of Treichville, Felix Houphouet-Boigny University, Abidjan, Côte d'Ivoire.
\end{abstract}

\section{ABSTRACT}

Africa trails the rest of the world in COVID-19 cases and deaths. However, as the pandemic spreads through the continent, we expect increases in community infection in the months ahead. Patients with kidney disease, especially those with end-stage kidney disease and those with kidney transplants, are at high risk for acquiring the disease and dying from it. While there is limited evidence for the benefit of interventions, we have the advantage of learning from the experiences of those in China, Europe and the Americas. This document sets forth guidance for dealing with our patients who have acute and chronic kidney disease, including those on renal replacement therapy and the staff involved in their care. Emphasis is placed on preparedness and prevention strategies. As evidence and experience accumulate, it is likely that updated guidance will be needed.

L'Afrique suit le reste du monde en termes de nombre de cas et de décès dus à COVID-19. Cependant, alors que la pandémie se propage à travers le continent, nous prévoyons une augmentation de l'infection communautaire dans les mois à venir. Les patients atteints d'une maladie rénale, en particulier ceux atteints d'une maladie rénale chronique en phase terminale et ceux ayant subi une transplantation rénale, courent un risque élevé de contracter la maladie et d'en mourir. Bien que les preuves d'interventions soient limitées, nous avons l'avantage de tirer des enseignements des expériences de ceux qui se trouvent en Chine, en Europe et dans les Amériques. Ce document présente des conseils pour traiter nos patients atteints d'insuffisance rénale aiguë et chronique, y compris ceux sous thérapie de suppléance rénale et le personnel impliqué dans leurs soins. L'accent est mis sur les stratégies de préparation et de prévention. Au fur et à mesure que les preuves et l'expérience s'accumulent, il est probable que des directives actualisées seront nécessaires.

Keywords: COVID-19; Africa; dialysis; transplantation; acute kidney injury. 


\section{CONTENTS}

I. Introduction

2. Background information considered
2.1. Virus-related issues
2.2. Patient-related issues
2.3. CKD-related issues
2.4. Case definitions

3. Chronic kidney disease

4. Chronic haemodialysis guidance

4.I. Guidance for government authorities

4.2. Guidance for treatment centres

4.3. Guidance for patients

5. Dialysis preparedness checklists

6. Suggested triage mechanism

7. Dialysis prescription in chronic HD patients with COVID-19

8. Contact tracing

9. Strategies regarding COVID-19 in PD patients

10. Guidelines for management of AKI in the context of COVID-I 9 infection
10.1. Definition of AKI
10.2. Pathophysiology and burden of AKI associated with COVID-19
10.3. Management of AKI in COVID-19 patients
10.4. Dialysis modalities
10.5. Patient and staff care
10.6. Vascular access
10.7. Care and disinfection of dialysis equipment
10.8. CRRT and SLED in the ICU
10.9. Suggested prescription
10.10. Anticoagulation
10.1 I. Drug modification in COVID-19 patients undergoing dialysis

II. Guidelines for kidney transplant recipients
I I.I. Epidemiology
11.2. Recommendations
11.3. Management of immunosuppressive medication
1 1.4. When to resume immunosuppressive therapy
1 1.5. Drug interactions

I2. Concluding remarks 


\section{INTRODUCTION}

COVID-19 is a condition caused by the SARS-CoV-2 coronavirus. This novel virus has spread around the world and has caused significant fatalities in many countries. The virus's impact on health systems and economies has caused widespread distress.

On the African continent, the virus has been documented in all 47 countries, with almost 85,000 cases and 2,760 deaths as at 16 May 2020 [1,2]. Public health guidelines prepared by various international organizations and countries are widely available and give advice to prevent infection in the general population. This document gives guidance on the specific issues relating to the prevention of COVID- 19 infection and the care of affected patients with kidney disease.

\section{BACKGROUND INFORMATION CONSIDERED}

\section{I. Virus-related issues}

a. It is a highly infectious virus with an RO factor (the number of new infections estimated to arise from a single case) of approximately 3 (compared to influenza with an R0 of approximately I) [3]. Efforts to reduce the spread may lower the R0 to $<1$ in some areas.

b. It is spread by droplets from the respiratory tract laden with virus - this may contaminate fomites and surfaces. Direct airborne spread may occur if a carrier is in close proximity ( $<2$ metres) when droplets are expelled. Aerosolised virus may persist for a period in the air but the significance is not yet clear [4].

c. Asymptomatic individuals may spread the virus although the frequency of this is not known [5].

d. Masks worn by infected persons may reduce environmental contamination by viral particles [6].

e. Virulence in an immune naïve population may result in significant fatalities (0.5-5\%). The mortality estimates are affected by the testing strategy. Mortality rates may be lower if undiagnosed, asymptomatic cases are accounted for [7].

f. Infection is currently diagnosed by nucleic acid detection methods using a reverse transcriptase polymerase chain reaction (RT-PCR) technique. Nasopharyngeal swabs are currently preferred but sputum, tracheal aspirates or broncho-alveolar lavage fluid (if available) are more sensitive. Saliva may be an option in future. Negative tests do not rule out infection completely and may need to be repeated if the index of suspicion remains high [8].

\subsection{Patient-related issues}

a. Asymptomatic infection is common [5].

b. Mortality is higher in the elderly and patients with comorbidities including hypertension, diabetes, asthma, cardiac disease, chronic kidney disease (CKD) and patients on immunosuppression [9].

c. Genetic susceptibility or protection is not proven.

d. Mortality seems lower in Africa, although there is no proven reason. This may be a false impression as numbers of infections are still relatively low.

e. Infection and viral shedding may persist for several weeks. The implications for infection control remain unclear. Recent data suggest that it is unlikely that live virus is shed beyond the second week of infection [10].

\subsection{CKD-related issues}

a. Mortality is higher in patients with CKD [I I]

b. Chronic haemodialysis (HD) patients are vulnerable due to their frequent travel for dialysis, regular contact with dialysis staff and other patients and multiple comorbidities. They also have a higher mortality $[12,13]$.

\subsection{Case definitions}

a. Confirmed case: a person who has tested positive for the SARS-CoV-2 pathogen in accordance with testing standards, irrespective of clinical signs and symptoms.

b. Suspected case: a person who develops a fever $\geq 37.5^{\circ} \mathrm{C}$ or respiratory symptoms such as coughing or difficulty breathing within 14 days of coming into contact with a confirmed case while that patient was symptomatic.

c. Contacts: contacts are identified after epidemiological investigation and include patients who received HD on the same shift as a confirmed case, patients who received HD without proper prior disinfection of equipment after HD of a confirmed case, and patients or healthcare workers who were exposed (within 2 metres) to a confirmed case without adequate personal protective equipment (PPE).

These guidelines draw from international and local experience with this disease. As expected in a rapidly developing pandemic, there is a paucity of high-quality evidence. Individual centres will have to adapt guidance provided based on the unique circumstances in their countries as well as available resources.

The International Society of Nephrology (ISN) [12] and the European Dialysis and Transplant Association (EDTA) [13] have dedicated web pages with collected resources and recommendations.

\section{CHRONIC KIDNEY DISEASE $[14,15]$}

Patients with CKD stages $3-5$ have been identified as a high-risk group for COVID-I 9 complications. Many have hypertension, diabetes and coronary artery disease, which are additional risk factors. Many patients are on immunosuppression for glomerular or multisystem diseases. 
a. Many patients in this group are on angiotensin-converting enzyme (ACE) inhibitors or angiotensin II receptor blockers (ARBs). It has been speculated that these increase the risk of complications, but this is unproven and has not been observed in clinical settings thus far. Patients should not stop their prescribed medicines, including ACE inhibitors or ARBs, unless indicated for other reasons $[16,17]$. Patients should have sufficient amounts of medicines to avoid frequent visits to clinics or pharmacies. If possible, medicines should be delivered to patients and several months' supply may be included where safe.

b. Patients should practise social distancing, wear cloth masks on leaving home, practise hand hygiene as prescribed by authorities and perform regular surface disinfection.

c. Patients should be educated about symptoms (see below). If symptomatic, they should call ahead to determine the procedures for triage and testing based on local protocols.

d. Routine visits to treating doctors should be curtailed and, where possible, replaced with telephonic or online consultation.

e. Group activities should be cancelled.

f. Patients on immunosuppression should not stop their medicines without discussion with treating physicians. It may be possible to reduce or change immunosuppressive therapies based on the risk of the disease being treated. Patients with new or rapidly worsening disease may require ongoing or increased immunosuppression $[18,19]$.

g. Acute kidney injury $(A K I)$ is more common in patients with CKD. Patients should avoid nephrotoxic agents and drug doses should be modified during treatment for COVID- 19.

h. Psychological support may be needed to prevent anxiety, depression or other problems which could impact on adherence to therapy and patient well-being.

\section{CHRONIC HAEMODIALYSIS GUIDANCE}

\section{I. Guidance for government authorities}

Governments should include haemodialysis units in their integrated plans for dealing with the COVID-19 pandemic. These should include:

a. Acknowledging the high risk of patients with kidney disease as noted above.

b. Accommodation and concessions in lockdown regulations to allow travel to and from treatment centres for patients and staff.

c. National, local and regional plans for different scenarios including dealing with isolated or high-volume outbreaks.
These may include dedicated COVID-19 units and cohorting of patients.

d. Ensuring adequate PPE provision to units dealing with COVID-19 in sufficient quantities to protect staff and optimize care of patients. Note the recent guidance from the Centers for Disease Control and Prevention (CDC) and World Health Organization (WHO) [2028]. See further guidance below.

e. National guidelines on staff policies including nonpunitive, sick-leave policies and return to work policies should be formulated [25].

f. National authorities should plan for an increase in demand for renal replacement therapy (RRT) related to AKI. This may require the acquisition of additional equipment and the training of staff. International and regional cooperation with assistance from the African Association of Nephrology (AFRAN) and the International Society of Nephrology (ISN) may be required to facilitate this. Equipment which can offer continuous or hybrid therapies is preferred.

\subsection{Guidance for treatment centres $[13,20$, 22-25]}

\section{Patient information and education}

a. Signage and information should be available to educate patients about COVID-19 and the triage processes in the unit. Signage must be prominent and easy to understand, even by those with limited literacy.

b. Patients should be educated on handwashing, sanitizing and masking procedures.

c. Patients should be aware of symptoms and signs to look out for.

d. Patients with symptoms should be aware of the procedures to follow.

\section{All staff should receive detailed training on the following aspects:}

a. Understanding the basics of the disease including mechanisms of spread.

b. Recognizing symptoms and triage of suspected cases.

c. Proper handwashing, sanitization and universal precautions. These include handwashing with soap and water for at least 20 seconds or using a hand sanitizer which contains at least $60 \%$ alcohol. Avoidance of touching of the face should be emphasized.

d. The importance of universal masking at all times by all patients and staff. Cloth masks for patients may be acceptable provided they conform to quality recommendations as set out by local authorities. See CDC guidance at https://www.cdc.gov/coronavirus/20 I9-ncov/ prevent-getting-sick/diy-cloth-face-coverings.html [29]. 
e. Donning and doffing of PPE - see guidance from the CDC and $\mathrm{WHO}[24,26,27]$.

f. Disinfection of surfaces and the environment as per protocols (see below).

g. Unit protocols for suspected and confirmed cases (see below).

h. "What do you do if you suspect you have been exposed?"

\section{Procedures if a staff member is ill}

Staff policy on sick leave should be non-punitive, to encourage staff to report their symptoms timeously. In severely staff-constrained settings, personnel who have been exposed may need to continue working while wearing masks and with adequate hand sanitization unless proven positive or symptomatic. Staff should not move between units.

\section{Staff facilities}

Staff eating and common areas should not be filled to the point where physical distancing is not possible. This will require staggered mealtimes and the suspension of group activities or staggered group activities such as prayer and training.

All staff and patients should be screened daily for fever $>37.8^{\circ} \mathrm{C}$.

\section{Provision of PPE}

Adequate supplies of PPE and cleaning equipment should be made available. See $\mathrm{WHO}$ and CDC guidance and recent advice from the Kenyan Renal Association [24,26, 28]. Dialysis staff should employ standard contact and droplet precautions, including isolation gowns, gloves, masks, and eye protection (shields or goggles), as appropriate (Figure I). Because PPE will need to be deployed for many weeks or months in this current pandemic, care must be taken to establish policies that will not exhaust the available supplies of these precious resources.

a. Face masks - standard surgical face masks are acceptable if N95 masks are in short supply. These respirators should be prioritized for procedures that are likely to generate respiratory aerosols. Cloth masks or surgical masks should be used by patients and clinical personnel at all times in public spaces.

b. Eye protection - eye shields or goggles should be used by personnel caring for patients with COVID-19 to avoid droplet spread via the eyes. Reusable shields and goggles should be cleaned and disinfected according to manufacturers' instructions.

c. Gowns - gowns or plastic aprons should be worn over laboratory coats, scrub suits or street clothes. If gowns are in short supply, they should be prioritized for

\section{PREFERRED PPE - USE N95 OR HIGHER RESPIRATOR}

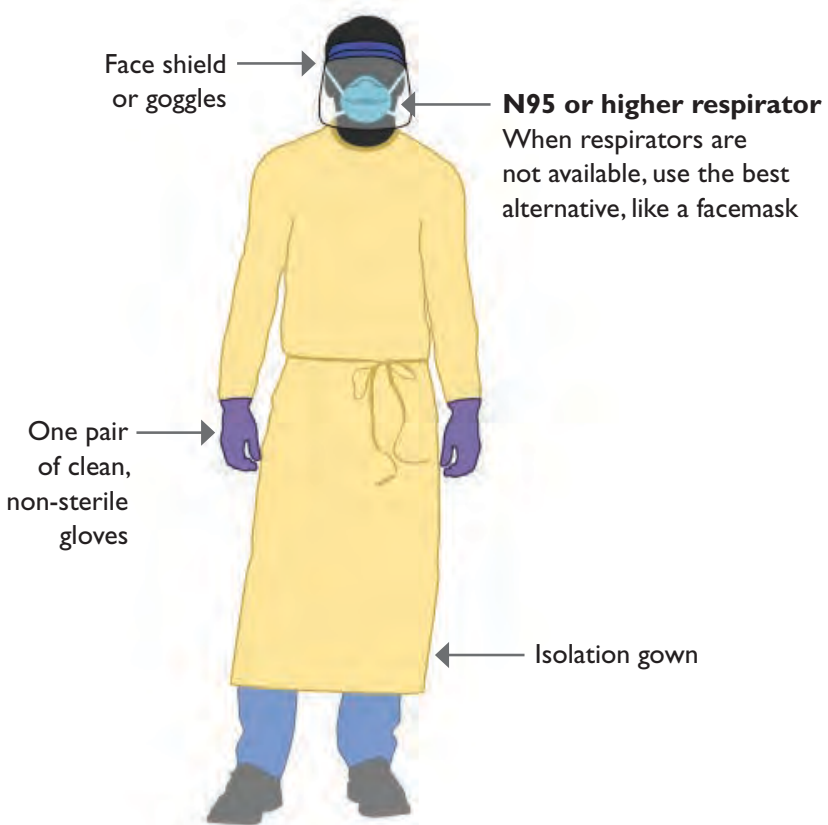

\section{ACCEPTABLE ALTERNATIVE PPE - USE FACEMASK}

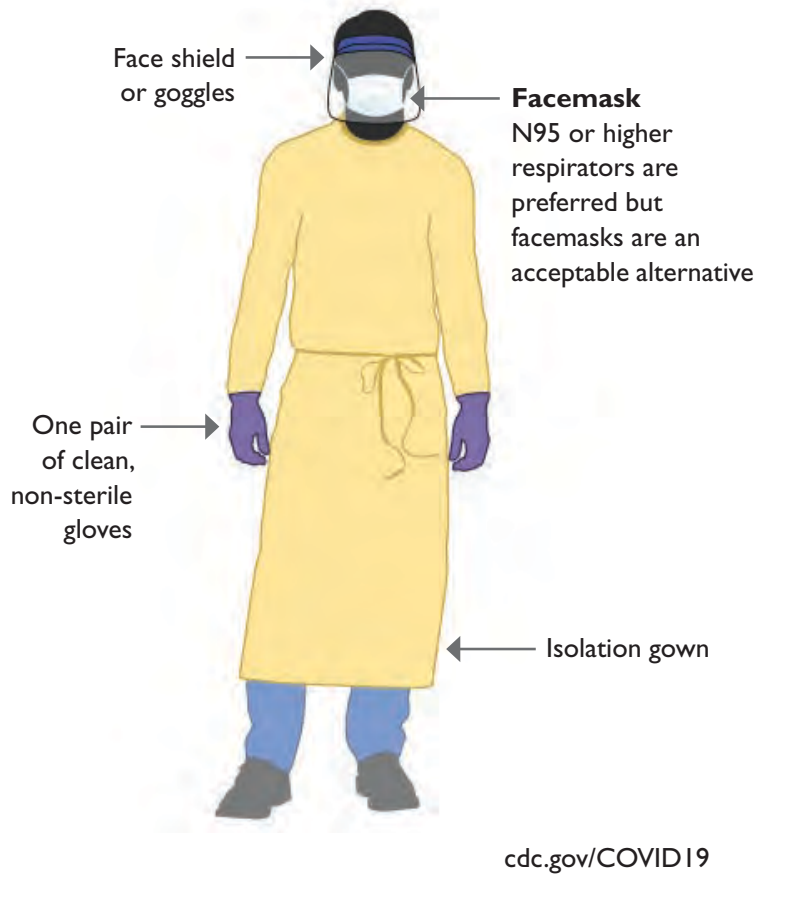

Figure I. CDC recommendations on acceptable PPE for healthcare workers caring for patients with COVID-I9. 
initiating and terminating dialysis, manipulating access needles and catheters, assisting patients to and from the dialysis stations, and cleaning and disinfecting the dialysis station.

d. Shoe covers - these may be needed to prevent spread via footwear to clean areas of the unit.

\section{Scenario planning by treatment centres}

Treatment centres should have a detailed plan based on different scenarios they may face. Because of the variations in unit size, staffing, support structures and resources, this should be individualized and drawn up together with other local authorities and support groups. This will include policies on testing and contact tracing.

a. Scenario planning based on numbers of expected cases can differ.

b. At the very least, the unit should plan for the following:

i. A triage or screening process to identify suspected or high-risk cases. This would include temperature screening, symptom screening and eliciting a history of contacts. This may be done prior to arrival at the unit.

ii. Separate waiting areas for suspected cases and confirmed cases.

iii. Spacing in waiting areas should allow for social distancing. Patients should not arrive too early. They may wait in cars or outside the building, depending on the climate and available facilities. An SMS or electronic notification system could be set up to inform patients when their station is prepared.

iv. An area where at-risk or suspected patients can be dialysed, which is separated from other patients or at least by 2 metres. Where possible, an isolated negative pressure room is ideal (such as a nonhepatitis $B$ area).

v. An area or time where confirmed COVID-19positive patients can be dialysed. Depending on circumstances and numbers, this could take various forms including a dedicated unit in the area, a dedicated isolation area or a dedicated shift. At the very least, the patient should be dialysed at the end of the loop, separated by at least 2 metres from other patients and nursed by a dedicated staff member equipped with PPE.

Cleaning of dialysis machines, equipment and chairs [22, $25,28,30,31]$

a. All dialysis machines, dialysis chairs, surrounding surfaces and equipment must be disinfected with appropriate cleaning agents. This includes BP cuffs and stethoscopes.

b. Clean and disinfect frequently touched surfaces at least thrice daily and after every shift. These include bedside tables and lockers, dialysis machines, doorknobs, light switches, counter tops, handles, desks, phones, keyboards, toilets, faucets and sinks, etc.

c. As most sphygmomanometer cuffs are now made of artificial leather (Rexine), they should also be cleaned using alcohol or hypochlorite-based (I\% sodium hypochlorite) solutions; however, the individual manufacturer's manuals should be referred to.

d. Individual cleaning cloths need to be used for cleaning each machine and dialysis chair and discarded post cleaning.

e. Fresh water with appropriate disinfectant needs to be used for cleaning each dialysis machine and chair. Water must be flushed down the sluice when cleaning is completed.

f. Almost all common disinfectant solutions are effective in killing the virus on surfaces. The key is effective and frequent cleaning. It is recommended that solutions for disinfection be composed either of hypochlorite, alcohol, formaldehyde or glutaraldehyde, in accordance with the manufacturer's instructions.

g. Cleaning-cloths and water should never be shared among dialysis machines and chairs.

\section{Linen management $[22,25,28,30,31]$}

a. All onsite and offsite facilities that process or launder linen for healthcare facilities must have documented operating policies consistent with regulations.

b. Handle all used linen with care to avoid dispersal of microorganisms into the environment and to avoid contact with staff clothing.

c. Manage all linen used for a person suspected or confirmed to have COVID-19 infection as for heavily soiled linen.

d. Wear a long-sleeved, fluid-resistant gown and disposable gloves during handling of soiled linen, to prevent skin and mucous membrane exposure to blood and body fluids.

e. Remove the long-sleeved gown and disposable gloves and perform hand hygiene following the handling of used linen.

f. Linen should be machine washed with a water temperature $>60^{\circ} \mathrm{C}$.

\subsection{Guidance for patients}

4.3.1. Patients should not miss dialysis sessions.

4.3.2. Patients should be provided with the necessary documents/permits in the event of lockdowns or curfews.

4.3.3. Patients should be educated about prevention strategies including:

a. Hand hygiene 

b. Cough etiquette
c. Avoiding touching the eyes, mouth and face
d. Avoiding symptomatic friends, family and col- leagues
e. Masking in and out of the dialysis unit
f. Avoiding crowds and social distancing
g. Vaccination against influenza and pneumococcus
h. Avoiding travel and movement between dialysis units.

4.3.4. Patients should self-screen for symptoms at home before each dialysis session.

4.3.5. Signs and symptoms of COVID-19 include:
a. Fever
b. Cough
c. Diarrhoea
d. Malaise
e. Shortness of breath or difficulty breathing
f. Loss of smell or taste
g. Sore throat
h. Influenza-like illness
i. Some patients have no symptoms.

4.3.6. Patients should advise if they have a recent travel history or exposure to a case of COVID-19.

4.3.7. People who are older or have existing medical conditions, such as heart disease, lung disease or kidney disease, may be at higher risk of serious illness.

4.3.8. The usual vaccinations (hepatitis $B$, influenza, etc.) should be continued even in patients with COVID-19 (https://apps.who.int/iris/bitstream/handle/ I0665/33 I 590/WHO-20 I 9-nCoV-immunization_ services-2020.1 -eng.pdf) [32].

4.3.9. Patients with symptoms should be advised on the procedure of triage and testing.

4.3. 10. Patients should preferably not eat inside the dialysis units or waiting rooms. Some diabetic patients may require a snack to prevent hypoglycaemia.

4.3.I I. Patients should avoid shaking hands or sharing items.

4.3.12. All patients requiring hospital admission should be tested for COVID- 19 prior to or upon admission.

\section{DIALYSIS PREPAREDNESS CHECKLISTS}

Checklists can be used to assess preparedness of dialysis units for the triage and management of COVID-19 cases. Examples are available through the George Institute for Global Health [21,] and the CDC [33]. Alternatively, local authorities may create area-specific checklists using the

\section{SUGGESTED TRIAGE MECHANISM}

6.1. The goal of triage is to prevent spread of the disease in the dialysis unit to protect a vulnerable population. The risks of spread are aggravated by the following:

a. The requirement for patients to aggregate at the dialysis unit in shifts, with difficulty separating them in time and space.

b. The use of shared transport by patients.

c. Asymptomatic carriage of the virus by staff and patients.

d. The need for physical contact of patients with staff and equipment for treatment.

e. The prolonged duration of treatment.

6.2. A dedicated triage area (see Figure 2) outside the treatment area should be used for a risk check of the patient for the following:

a. Positive contact or recent travel.

b. Temperature check.

c. Symptoms of COVID-19.

d. If any of the above are of concern, the patient should be evaluated by a doctor and risk stratified. Further tests may be required.

6.3. Patients and staff can be separated into three categories:

a. Low risk - no symptoms, normal temperature, no risk factors.

b. Moderate risk - mild/nonspecific symptoms, temperature $37.2-37.8^{\circ} \mathrm{C}$, possible contact, normal tests such as ferritin, C-reactive protein (CRP), D-dimer, chest $X$-ray $(C X R)$ or computed tomography (CT) scan of the chest.

c. High risk - specific symptoms, positive close contact, fever $>37.8^{\circ} \mathrm{C}$, abnormal ferritin, CRP, D-dimer, CXR or chest CT scan.

6.4. All patients and staff should wear a mask in all areas.

6.5. Screening should include staff members.

6.6. Low-risk patients may continue dialysis as usual.

6.7. For moderate- and high-risk patients:

a. Check urea, creatinine and electrolytes, CRP, ferritin and D-dimer.

b. Do nasopharyngeal swab test for PCR for SARSCoV-2.

c. Perform CXR and check oxygen saturation.

d. Dedicated COVID- 19 units may be allocated in each region with sufficient staff and PPE.

e. A dedicated area of the unit separated by at least 2 metres from any other patient may be used, provided all patients are masked and the patient is nursed by a dedicated staff member with appropriate PPE. 
f. A dedicated shift at the end of the day with full disinfection and terminal cleaning may be considered.

6.8. Patients may be de-isolated [34]:

a. If asymptomatic - 14 days after the positive result.

b. If symptomatic - 14 days after clinical stability.

6.9. Because of the need for ongoing contact after deisolation, repeat COVID-19 PCR testing may be appropriate. However, there is evidence that prolonged viral shedding is possible with patients not being infectious despite this [10].

6.10. Staff who test positive should be removed from duty and can also be de-isolated as per the above guidelines.

\section{DIALYSIS PRESCRIPTION IN CHRONIC HD PATIENTS WITH COVID-I 9}

7.I. The cytokine storm associated with raised IL6, ILI8 and IFN gamma is associated with poorer outcomes [35].
7.2. Patients who are stable may continue with their chronic dialysis prescription and should not miss treatment sessions. High-flux dialysis membranes (with a sieving coefficient for myoglobin of $>0.5$ ) are recommended for maximal dialysis efficiency. Careful attention to fluid balance and ongoing symptomatology is required. Deterioration should trigger escalation of therapy. Patients should be dialysed in a designated area [20].

7.3. Patients with acute deterioration and those in an intensive care unit (ICU) should receive an individualized, daily dialysis prescription.

7.4. Dialysis modalities used will depend on staff competencies and the availability of equipment and consumables. Centres should use modalities with which they are familiar.

7.5. High-volume (> $35 \mathrm{~mL} / \mathrm{kg} / \mathrm{h}$ effluent) continuous haemofiltration (CVVHF) or haemodiafiltration (CVVHDF) may allow cytokine removal to alleviate cytokine storm-related complications [36,37].

7.6. HDF may be preferred for intermittent treatments but no supporting data are available.

\section{SCREENING AT HOME OR ON ARRIVAL FOR TREATMENT}

I. Fever, dyspnoea, cough, sore throat, malaise

2. Influenza-like illness

3. History of contact with a confirmed case of COVID-19

4. History of travel in the last 14 days

5. History of contact with patients with unexplained fever or respiratory symptoms
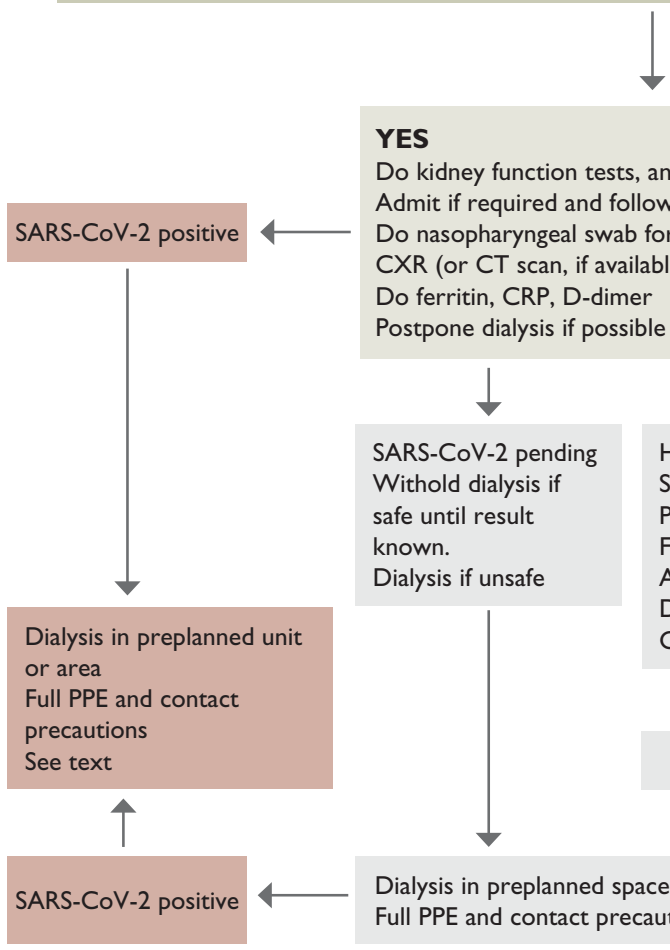

YES

Do kidney function tests, and clinical assessment Admit if required and follow inpatient protocols

Do nasopharyngeal swab for PCR for SARS-CoV-2 CXR (or CT scan, if available)

Do ferritin, CRP, D-dimer

Postpone dialysis if possible until results known

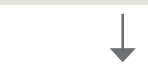

SARS-CoV-2 pending

Withold dialysis if

safe until result

known.

Dialysis if unsafe

HIGH RISK

Specific symptoms

Fever $\left(>37.8^{\circ} \mathrm{C}\right)$

Abnormal ferritin, CRP,

D-dimer, CXR or

CT chest

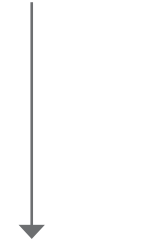

Dialysis in preplanned space for persons under investigation

Full PPE and contact precautions

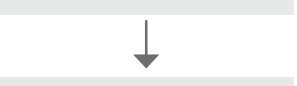

Retest in $48 \mathrm{hrs}$

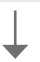

Positive close contact
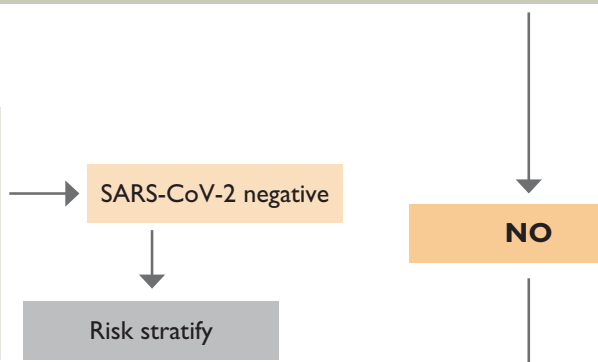

MODERATE RISK

Mild or nonspecific symptoms

Borderline temperature $\left(37.2-37.8^{\circ} \mathrm{C}\right)$

Possible contact - not confirmed

Normal ferritin, CRP, CXR or CT chest

SARS-CoV-2 negative

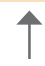

Figure 2. Suggested screening and triage algorithm for dialysis units. 
7.7. Hybrid treatments like prolonged intermittent renal replacement therapies (PIRRT) and sustained lowefficiency dialysis (SLED) may also be used in haemodynamically unstable patients.

7.8. See section on treatment of AKI for more information regarding dialysis prescriptions.

7.9. Peritoneal dialysis may be safely employed as therapy even in acute settings. See section on AKI for further information [38].

\section{CONTACT TRACING [34]}

8.1. There is a paucity of high-quality evidence on this topic. Figure 3 shows examples of different scenarios.
More information is available from the National Institute for Communicable Diseases (NICD) in South Africa [34].

8.2. If a positive case is found:

a. Close contacts of the case must be traced from at least the time of first symptoms or 48 hours prior. They include dialysis unit staff who had direct contact with or nursed the patient without appropriate PPE. If the patient was masked at all times in the unit, the risk to adjacent patients is smaller.

b. Close contacts should be screened for symptoms and asked to self-isolate. They should be tested if appropriate. Staff may need to stay at home, if

\section{SCENARIO I:} worker with a positive COVID-19 test

Place on sick leave
(disinfect workspace if
applicable)

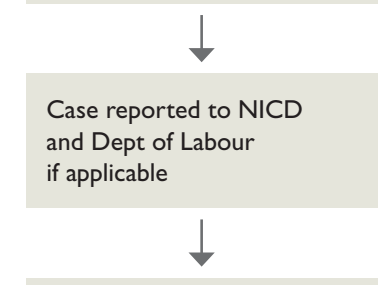

Self-isolate at home

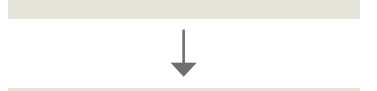

Return to work 14 days after symptom onset (mild cases)

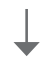

Return to work 14 days after clinical stability e.g. after oxygen is stopped (severe cases)
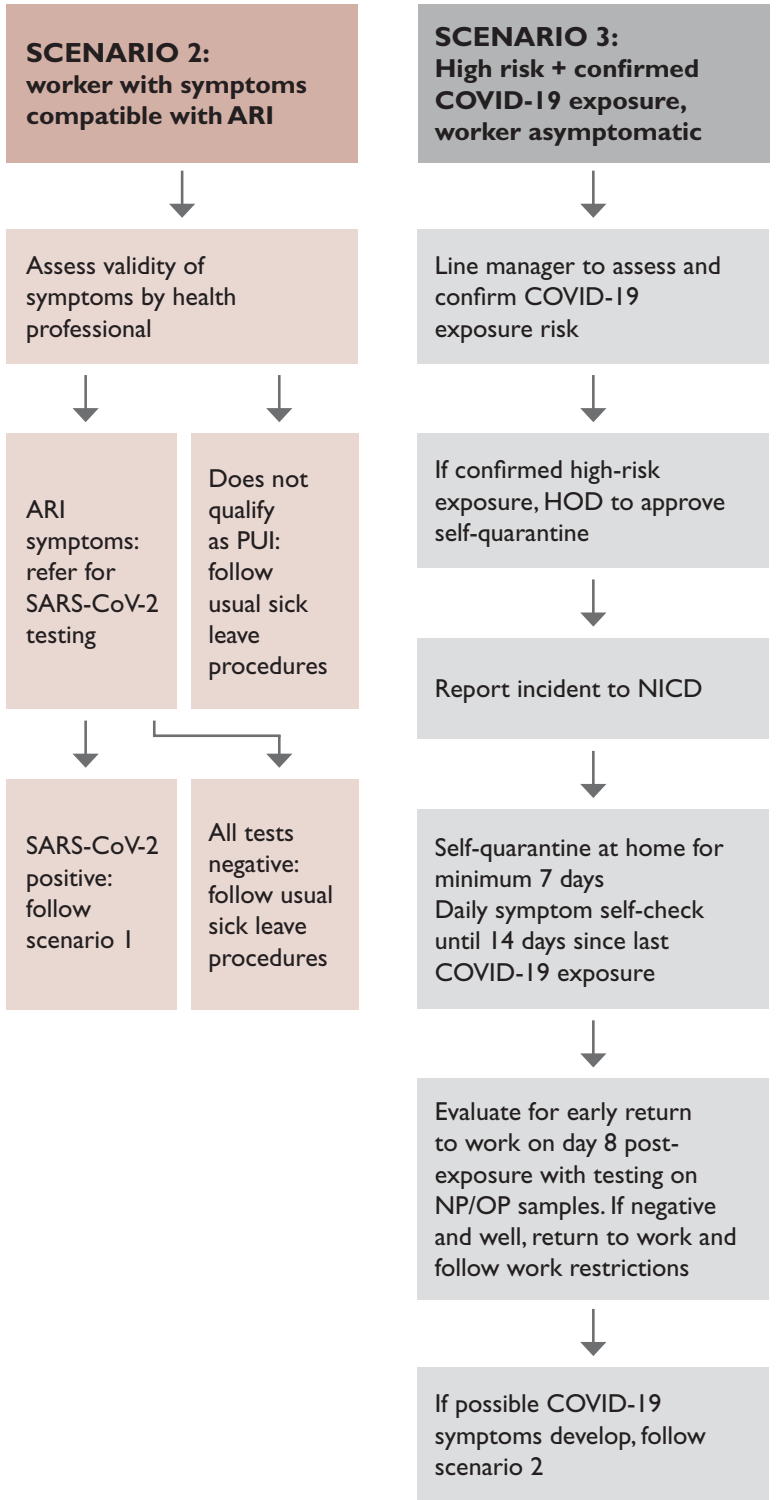

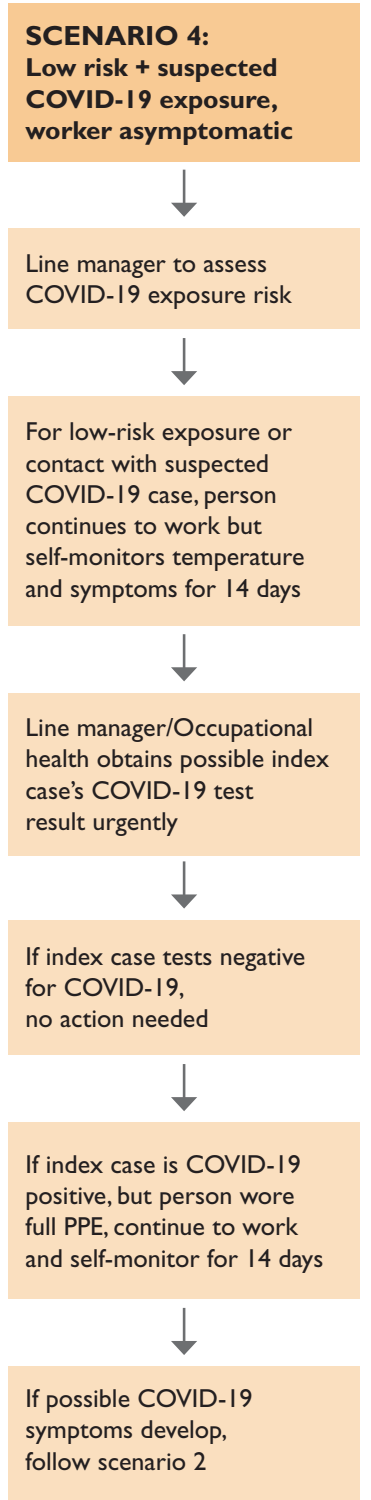

Figure 3. Possible scenarios for dealing with exposed staff members (per NICD). 
resources allow, until testing can occur. A riskbased assessment can be carried out based on type of contact and presence of symptoms. A line manager should be delegated to decide on type of risk.

c. The optimal time for testing is not known, although it is recommended that testing be done upon symptom onset or 5-7 days after contact.

8.3. If the RT-PCR test is negative, follow the proposed guidelines in Figure 3.

\section{STRATEGIES REGARDING COVID-I 9 IN PD PATIENTS [39]}

This is the summary of guidelines issued by the International Society of Peritoneal Dialysis, which can be accessed at https://ispd.org/strategies-covid I9/.

People on PD should stay at home. Hospital visits should be undertaken only for urgent indications (for example, suspected peritonitis). Consultations should otherwise be conducted using telehealth. If needed, consultations should be timed to avoid long periods in a waiting area. All patients should wear a mask when outside their homes.

I. Normal universal precautions and handwashing must be applied everywhere at all times. Surface disinfection should be regularly carried out.

2. Continued education and training of staff about COVID-19 is recommended for every PD unit. Selfmonitoring for COVID- 19 for individual healthcare staff members and screening tests for suspected cases is recommended.

3. At home, patients should have at least 2 weeks of PD supplies and sufficient medications in case they must self-isolate, or if there is a break in the supply chain.

4. In the PD unit, non-essential procedures, for example PET or clearance measurements, should be avoided to minimize unnecessary patient contact.

5. Patients should be educated regarding symptoms of the disease.

6. Patients should be advised also to call in rather than present unannounced to units if they are symptomatic or have been in contact with a confirmed case.

7. Once determined as having had potential exposure to the virus, or COVID-19-related symptoms, patients should have the necessary viral swab tests by a designated team, depending on local practice.

8. Elective and non-urgent admissions should be rescheduled, and inpatient elective surgical and procedural
9. For PD patients with confirmed disease, barrier measures must always be applied. This includes self-isolation at home. If patients need help with performing PD, caregivers should wear PPE.

10. Mildly or moderately ill COVID-19-positive patients can continue PD treatment as usual, with prescription adjustment according to evaluation.

II. Severely or critically ill COVID-19-positive patients requiring life support due to multiple organ dysfunction syndrome can be temporarily transferred to automated peritoneal dialysis or to haemodialysis.

12. Precautionary measures for PD staff performing inhospital dialysis is essential.

13. Personal protective equipment should be available for all members of the PD team.

14. Universal hygiene measures must be strictly observed by healthcare staff.

15. In hospitals, effluent from PD bags should be discarded as medical waste. At home, patients may discard the fluid in the toilet (preferably after adding bleach to the fluid or the toilet). Aerosols can be generated by toilet flushes, so the toilet lid should be shut before flushing. Uninfected persons should not do this without wearing PPE. Bags can be double-bagged and kept for three days before discarding [40].

\section{GUIDELINES FOR MANAGEMENT OF AKI IN THE CONTEXT OF COVID- I 9 INFECTION}

Figure 4 is a suggested management algorithm for patients with AKI in the context of COVID-19 [4I].

\section{0.I. Definition of AKI [42]}

Kidney Disease Improving Global Outcomes (KDIGO) defines AKI as any of the following:

- Increase in serum creatinine by $0.3 \mathrm{mg} / \mathrm{dL}(26.5 \mu \mathrm{mol} / \mathrm{L})$ or more within 48 hours or

- Increase in serum creatinine to 1.5 times baseline or more within the last 7 days or

- Urine output less than $0.5 \mathrm{~mL} / \mathrm{kg} / \mathrm{h}$ for 6 hours.

KDIGO has also recommended a staging system for the severity of the AKI (Table I).

\subsection{Pathophysiology and burden of AKI associated with COVID-I 9}

AKI is more common among patients with more severe disease, particularly in ICU settings, and is considered a negative prognostic factor with respect to survival $[1$ I,43, 44]. It is thought that a maladaptive systemic inflammatory 


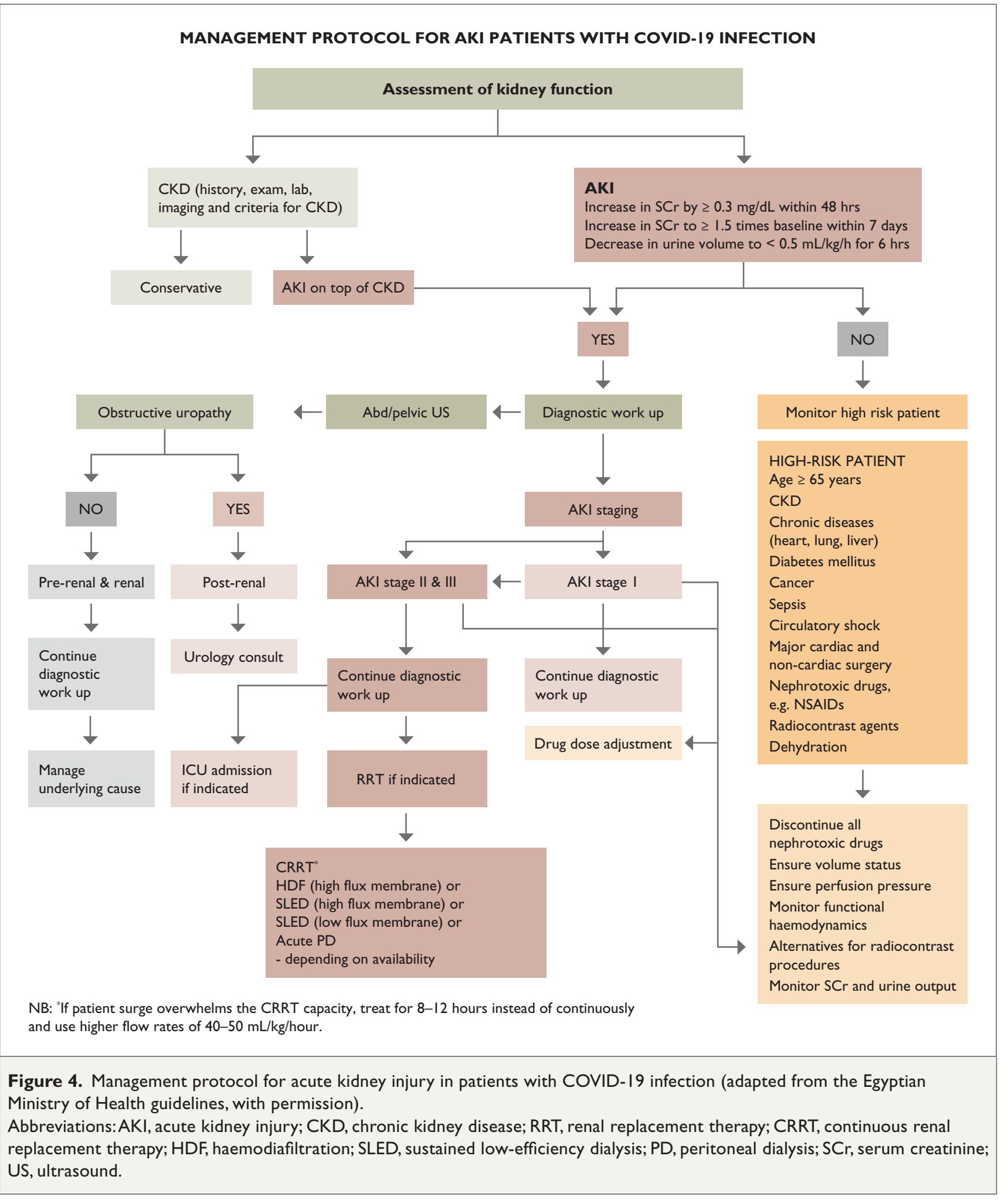

Table I. KDIGO classification of acute kidney injury [42].

$\begin{array}{cl}\text { Stage } & \text { Serum creatinine } \\ \text { I } & \begin{array}{l}\text { 1.5- } 1.9 \text { times baseline } \\ \text { or } 0.3 \mathrm{mg} / \mathrm{dL}(26.5 \mu \mathrm{mol} / \mathrm{L}) \text { increase }\end{array} \\ \text { II } & 2-2.9 \text { times baseline } \\ & \begin{array}{l}3 \text { times baseline } \\ \text { or } 4 \mathrm{mg} / \mathrm{dL}(354 \mu \mathrm{mo} / \mathrm{L}) \text { increase } \\ \text { or initiation of renal replacement therapy }\end{array}\end{array}$

Urine output

$\mathrm{mL} / \mathrm{kg} / \mathrm{h}$ for $6 \mathrm{~h}$

$\mathrm{mL} / \mathrm{kg} / \mathrm{h}$ for $12 \mathrm{~h}$

$0.3 \mathrm{~mL} / \mathrm{kg} / \mathrm{h}$ for $24 \mathrm{~h}$

or

anuria for $12 \mathrm{~h}$ 
immune response, in the face of a cytokine storm, contributes to hypoperfusion-related injury of the renal tubules $[35,37]$.

Some evidence suggests the possibility of a direct cytopathic effect of SARS-CoV-2. ACE 2 and members of the serine protease family, essential for viral uptake by host cells, are highly expressed on podocytes and tubular epithelial cells. Reports of albuminuria and haematuria in the setting of COVID-19, along with isolation of viral RNA from the urine, further supports potential viral tropism for the kidney [45].

AKI is common in the ICU setting, affecting up to $40 \%$ of patients, with a frequent need for dialysis [46-48]. Approximately $5 \%$ of hospital admissions require dialysis [48].

Inevitably, the question arises whether RRT should be approached differently in the acute care setting. If a cytokine storm is contributing to disease severity in COVID-19, then in theory convective-based clearance may be superior for removal of large-sized cytokines compared to diffusionbased modalities. While this argument has been made repeatedly in the management of sepsis, clinical evidence has been, at best, inconclusive [36].

Possible mechanisms by which COVID-19 patients may develop $\mathrm{AKI}$ include:

a. Pre-renal: hypovolaemia, cardiogenic or septic shock

b. Tubular: acute tubular injury (ischaemic or toxic), ACE 2-mediated

c. Interstitial: drug-induced

d. Vascular: renal vein thrombosis, thrombotic microangiopathy

e. Glomerular: collapsing glomerulopathy (not proven)

f. Post-renal factors.

\subsection{Management of AKI in COVID-I 9 patients}

Risk factors and comorbidities must be assessed. These include advanced age, smoking, diabetes mellitus, chronic obstructive airways disease, chronic liver or kidney disease, congestive heart failure and history of radiocontrast administration or other medicines that affect kidney function.

\section{Fluid resuscitation}

The need for prompt fluid resuscitation to restore euvolaemia and systemic haemodynamics in septic patients is well established. Growing evidence suggests that the cardiac output does not always increase in many critically ill patients when challenged with a fluid bolus.

a. The exact amount and precise timing of tapering such resuscitation is not established. With regard to $\mathrm{AKI}$, fluid resuscitation is based on the theory that restoration of circulating volume will improve renal perfusion [49]. b. The improvement of haemodynamic macrovascular parameters may result in the restoration of cortical renal perfusion but this does not occur in all cases of septic shock [50].

c. Fluids are not different from drugs and carry side effects such as the activation of cytokines, shedding of the capillary glycocalyx and adversely affecting the capacity of the kidney to adequately filter excess fluid and nitrogenous waste.

d. The recently released "hour-I bundle" recommends that fluid resuscitation should be performed in septic patients with hypotension or lactate $\geq 4 \mathrm{mmol} / \mathrm{L}$ with $30 \mathrm{~mL} / \mathrm{kg}$ of crystalloids [5l].

e. In adult patients admitted to the ICU with sepsis, a positive fluid balance after the first day was associated with an increased risk of AKI. Fluid overload increases mortality. Excess fluid has been shown to be a negative predictor for recovery of renal function [52,53].

f. Current international guidelines from the Surviving Sepsis Campaign recommend crystalloids for initial resuscitation and subsequent volume replacement, with albumin "when patients require substantial amounts of crystalloids". However, the debate on which type of fluid to use in the resuscitation phase is still open. A recent meta-analysis reported that crystalloids were less effective than colloids in stabilizing resuscitation endpoints such as mean arterial pressure, cardiac index and central venous pressure [54].

g. Finally, evidence supporting albumin use in patients with septic shock comes from the ALBIOS study in which albumin administration was used to replenish albumin instead of using it for treating hypovolaemia [55].

\subsection{Dialysis modalities}

Depending of the availability of the modality and/or trained personnel, the available modalities for RRT are:

a. Continuous renal replacement therapy (CRRT)

b. Prolonged intermittent renal replacement therapy (PIRRT) or slow low-efficiency dialysis (SLED) with high flux filters

c. Intermittent haemodialysis (IHD) with high flux filters

d. Peritoneal dialysis (PD) either as continuous ambulatory peritoneal dialysis (CAPD) or automated peritoneal dialysis (APD) or intermittent peritoneal dialysis (IPD). The use of acute peritoneal dialysis can be lifesaving and should be considered in settings where haemodialysis is not available $[56,57]$.

\subsection{Patient and staff care}

a. Nephrologists, dialysis and ICU staff should follow national guidelines for infection control for COVID-19 infection, that is, adopting PPE and safety guidelines during their interactions with patients $[26,57]$. 
b. Nephrologists should consider minimizing/avoiding daily contact with patients by collaborating with primary physicians - for example, the ICU physician if patient is admitted to their unit - and relying on them to convey relevant findings, such as volume status.

c. Indications to start RRT are as for other patients with AKI.

d. Accumulating evidence suggests that a delayed RRT initiation is safe [58].

e. Loop diuretics may be used in the management of volume overload, according to the treating physician's discretion.

f. If there is a lack of dialysis or ICU nurses, non-dialysis or non-ICU nurses may be recruited to monitor patients undergoing RRT, under the supervision of an ICU or dialysis nurse [57].

g. For patients on chronic PD, the dialysis can be continued as APD in hospital, to reduce the exposure of nursing staff. If volume control cannot be maintained with PD, the patient may need temporary haemodialysis [56, 57,59].

h. It is essential that contact precautions and guidelines in the use of PPE are adhered to at all times.

\subsection{Vascular access}

If a patient develops indications to start dialysis - or if a patient on chronic HD needs vascular access - a doublelumen internal jugular catheter (preferably) should be inserted. If this is not possible, a subclavian or femoral catheter may be used. This should be placed by the physician with the most expertise in placement of central venous catheters, e.g. a vascular surgeon, ICU physician or radiologist [32]. Ultrasound-guided placement is recommended, where available. Jugular catheters are more convenient when a patient needs to be in the prone position to facilitate ventilation.

\subsection{Care and disinfection of dialysis equipment}

a. CRRT filter changes can be performed every 72 hours. If the need exceeds the number of machines available, shorter periods (e.g. 12 hours) may be attempted using higher flow rates $(40-50 \mathrm{~mL} / \mathrm{kg} / \mathrm{h})$.

b. After treatments, dialysis equipment should be disinfected according to national guidelines. The equipment should be disinfected before being removed from the room. Additional cleaning may be needed before the machine can be used for another patient [57].

\subsection{CRRT and SLED in the ICU}

The preferred modalities for RRT in critically ill patients are continuous renal replacement therapies (CRRT) or sustained low-efficiency dialysis (SLED) and other hybrid treatments (PIRRT) [37,57]. CRRT is a commonly initiated treatment in the ICU. Indications include AKI with metabolic acidosis, hyperkalaemia, excessive uraemia or refractory fluid overload.

\subsection{Suggested prescription}

a. Modalities used will depend on the availability of staff and equipment and the clinical complexity of the case.

b. CVVH pre- and/or post-dilution with a prescribed dose 25-30 mL/kg/h (to obtain an administered dose 20-25 $\mathrm{mL} / \mathrm{kg} / \mathrm{h}$ ). In the presence of a cytokine storm higher doses may be required. The dose should be regularly reassessed to determine if treatment goals are being met [47].

c. CRRT is beneficial for maintenance of volume balance, haemodynamic stability, and to allow adequate nutritional support. It will improve the clearance efficiency of medium-sized and small molecular toxins and can maintain body temperature. CRRT is particularly indicated in patients with AKI who are suspected to have high levels of cytokines and with haemodynamic instability.

d. If a patient surge overwhelms the CRRT capacity at an institution, consideration should be given to using CRRT machines for prolonged intermittent treatments - for example 10 hours instead of continuous with higher flow rates - such as 40-50 mL/kg/h - and then using the machine for another patient, after cleaning as per institutional policies.

e. Prolonged intermittent or SLED techniques are not inferior to continuous therapies. High-flux membranes are essential, if available, in this context.

f. Advantages of SLED include its use in haemodynamically unstable patients, the ability to use equipment for multiple patients, reduced requirements for anticoagulation, lower cost and wider availability.

g. Intermittent (standard duration) haemodialysis can be used in stable patients.

h. High-quality water generated by reverse osmosis should be used for all therapies.

\subsection{Anticoagulation}

Patients with COVID-19 have a high risk of thromboembolic events and many centres use higher dosages of thrombosis prophylaxis than usual (often double-dose) [60, 61 ]. The choice of anticoagulation is based on the patient's need for systemic anticoagulants, the risk or presence of bleeding, and the available drugs and expertise. Choices include:

a. Regional citrate anticoagulation, where available.

b. Systemic heparinization with unfractionated heparin.

c. Treatment without using anticoagulants. 
Many COVID-19-infected patients requiring intensive care management show altered liver function values. This may be secondary to drug-induced hepatotoxicity as well as due to possible liver involvement. This is associated with an increased risk for citrate accumulation.

\subsection{Drug modification in COVID-19 patients undergoing dialysis [62]}

Dose adjustments should be discussed between the primary physician, the nephrologist and the clinical pharmacist. Note that these are not treatment recommendations.

a. Anti-viral therapy: no adjustment of dose required for example, lopinavir/ritonavir, darunavir/ritonavir, darunavir/cobicistat.

b. Hydroxychloroquine (note that there is no clear evidence of efficacy and some safety concerns have been raised): for CRRT no dose adjustment is required; for haemodialysis or peritoneal dialysis, administer $50 \%$ of the dose and monitor ECG for detection of QT prolongation.

c. Ribavirin: use not recommended in severe renal dysfunction.

\section{I. GUIDELINES FOR KIDNEY TRANSPLANT RECIPIENTS [63]}

Kidney transplant patients taking immunosuppression are at higher risk of complications from COVID-19 [64]. Information about this disease and its impact on transplantation is evolving rapidly, so the guidance may change over time. Many of the recommendations are based on experience with the CMV and BK viruses.

\section{I.I. Epidemiology}

Data on transplant patients are limited but increasing [6468]. The lymphocyte count is lower in those who require ICU care. It is not possible to tell if lymphopaenia is a manifestation of a more severe form of disease, or if it is a predisposing factor for severe disease. Many transplant recipients have medication-induced lymphopaenia. Close attention should be paid to transplant patients with suspected or confirmed COVID-19 infection who are lymphopaenic [69].

\section{| I.2. Recommendations}

\section{II.2.I Transplant programmes}

a. All transplant-related teams should develop plans to reduce the burden on the healthcare system and to mitigate against an interruption in the care of transplant patients. b. Temporary suspension of the living-donor kidney transplant programmes should be considered when donation can safely be deferred to a later date. This can be in consultation with local authorities.

c. If transplantation is required as a life-saving procedure, it can be conducted with appropriate assessment of donor and recipient risk, and with appropriate informed consent.

d. The continuation of deceased-donor programmes will depend on local guidelines. High rates of in-hospital infection with COVID-19, especially with reduced bed availability, may necessitate temporary suspension of the programmes. A decision on whether to continue with surgery may need to be made whenever a donor becomes available.

e. SARS-CoV-2 should be excluded in donors and recipients [70].

\section{I.2.2 Transplant centres}

a. Visits to outpatient clinics that are not critical should be either deferred or substituted with telemedicine.

b. Visitors to transplant wards should be restricted as much as possible.

c. Determine who can work remotely and ensure they have the resources to do so.

d. Develop messaging for patients about how and when to contact the transplant centre in case of illness.

e. Develop guidance for candidates and recipients about risk mitigation, including limiting exposure to large crowds, hand hygiene and avoidance of sick people.

f. Staff and facilities should be prepared to receive suspected or confirmed cases of COVID-19.

g. Guidance for which transplant recipients need evaluation, testing and management by the transplant centre, versus which can remain at home with close remote follow-up, should be developed.

h. Staff with respiratory symptoms should stay at home (national policies should be applied).

i. Testing of staff should be done according to national and local guidelines.

j. Prevention policies and procedures: national, local and institutional guidelines should be followed [57].

\section{I.2.3 Transplant donors}

a. In the case of a diagnosis of COVID-19 infection, the donor must be excluded from donation for at least three months. If the need for donation is urgent, then this can be considered on a case-by-case basis after at least 28 days from diagnosis.

b. In the case of close contact with a person diagnosed with SARS-CoV-2 infection, the donor shall be excluded from donation for at least 28 days. The donor should be closely monitored for the presence of COVID- 19. 
c. In the case of travel to high-risk areas for COVID-19 infection or being in close contact with a person travelling from such an area, the donor shall be excluded from donation for at least 28 days.

d. Donors within 28 days before donation should practise good hygiene ( $\mathrm{WHO}$ recommendations) and avoid crowded places and large gatherings [13,7I]

\section{I.2.4 Transplant recipients}

a. Transplant recipients should avoid travel.

b. Transplant recipients with higher risk of infection include those having had contact with COVID-19-infected people or contact within 14 days prior to the onset of the disease, those with a history of travel within the previous 14 days and those in contact with patients who have fever or respiratory symptoms

c. They should avoid elective clinic visits.

d. Transplant recipients with risk factors or suspicious symptoms should be instructed to call the transplant centre and avoid presenting to the clinic without notification to avoid inadvertent exposures.

e. They should be examined and evaluated according to local policies to exclude or confirm SARS-CoV-2 infection $[68,7 I]$.

\section{I.3. Management of immunosuppressive medication $[63,68,7 \mathrm{I}]$}

Figure 5 is a proposed algorithm for the adjustment of immunosuppression in patients infected with SARS-CoV-2.

a. Asymptomatic, stable patients with no knowledge of COVID-19 status require no change of immunosuppressive medication.

b. Mild disease (mild upper respiratory symptoms, temperature $<38^{\circ} \mathrm{C}$ and no dyspnoea, persistent chest pain or intensive cough, oxygen saturation on room air $>95 \%$, respiratory rate $<25 / \mathrm{min}$, no evidence of pneumonia on chest CT scan):

- For patients on triple therapy: stop mycophenolic acid (MPA)/azathioprine (AZA)/mTOR inhibitors (mTORi) and maintain dual therapy with calcineurin inhibitors (CNI) and steroids.

- On dual therapy: continue this. If dual therapy is a steroid-free regimen with CNI + MPA/mTORi, consider replacing MPA/mTORi with low-dose steroids. If on MPA+mTORi, consider replacing MPA or mTORi with low-dose steroids.

- Consider CNI dose reduction (to the lower bound of the therapeutic range according to the immunological risk) if there is no clear improvement over the first 3-5 days. c. Mild COVID-19 pneumonia (oxygen saturation 94-95\% in room air, respiratory rate $25-29 / \mathrm{min})$ :

- High-risk patient: (age 70+, risk factors such as diabetes, cardiac or pulmonary disease, heavy smoking, $\mathrm{BMI}>30 \mathrm{~kg} / \mathrm{m}^{2}$, eGFR $<30 \mathrm{~mL} / \mathrm{min} / 1.73 \mathrm{~m}^{2}$, lymphocyte depletion therapy within previous 3-6 months) - stop MPA/AZA/mTORi, stop CNI, increase (or start) steroids to $15-25 \mathrm{mg} /$ day.

- Not high-risk patient: stop MPA/AZA/mTORi, maintain on dual therapy $\mathrm{CNI}$-steroids. Reduce the cyclosporine dose to target trough levels of $50 \pm$ $15 \mathrm{ng} / \mathrm{mL}$ and tacrolimus levels of $3 \pm$ I ng/mL. Continue steroids in maintenance dose.

d. If anti-retroviral (lopinavir/ritonavir) treatment is necessary, stop CNI (to avoid severe drug interactions) and monitor as shown in Figure 5.

e. More severe COVID-19 pneumonia (oxygen saturation $<94 \%$ in room air, respiratory rate $\geq 30 /$ min, unstable or deteriorating course or requiring non-invasive ventilation or transfer to the ICU):

- Discontinue all immunosuppressive drugs, if possible. Increase/start steroids at 15-25 mg/day (or higher according to local practice). Carefully consider continuing with low-dose $\mathrm{CNI}$ in patients with higher risk of rejection [57].

\section{I.4. When to resume immunosuppressive therapy}

A proposed approach in severely ill patients is to resume the $\mathrm{CNI}$ at half of the previous dosage, starting at least 3 days after clinical resolution and after two negative swabs (one at discharge and one 3 days later), with the aim of gradually reaching a trough level of $3-5 \mathrm{ng} / \mathrm{mL}$ of tacrolimus or 200-300 $\mathrm{ng} / \mathrm{mL}$ of cyclosporine at the second hour (C2). Resumption of full-dose CNI dosage and maintenance of the prednisolone can be considered after 15 days free of symptoms and an additional negative swab. Caseby-case evaluation for re-initiation of MPA, AZA and $\mathrm{mTORi}$ is needed [72]

\section{I.5. Drug interactions}

a. There is a possible increase in the exposure of cyclosporine, tacrolimus and mTOR inhibitors with chloroquine/hydroxychloroquine. It is advised to monitor the trough levels of cyclosporine, tacrolimus and mTORi in this setting [62].

b. Patients starting anti-retroviral drugs that contain ritonavir or cobicistat must stop mTORi and CNIs. If the aim is to continue tacrolimus, it should be administered only when blood levels are $<5 \mathrm{ng} / \mathrm{mL}$ and the dose should not exceed $0.5 \mathrm{mg}$ (overall dose reduction to one-fifth or lower). Cyclosporine should be given 


\section{MODULATION OF IMMUNOSUPPRESSIVE MEDICATION FOR KIDNEY TRANSPLANT PATIENTS DURING THE COVID-I9 PANDEMIC}

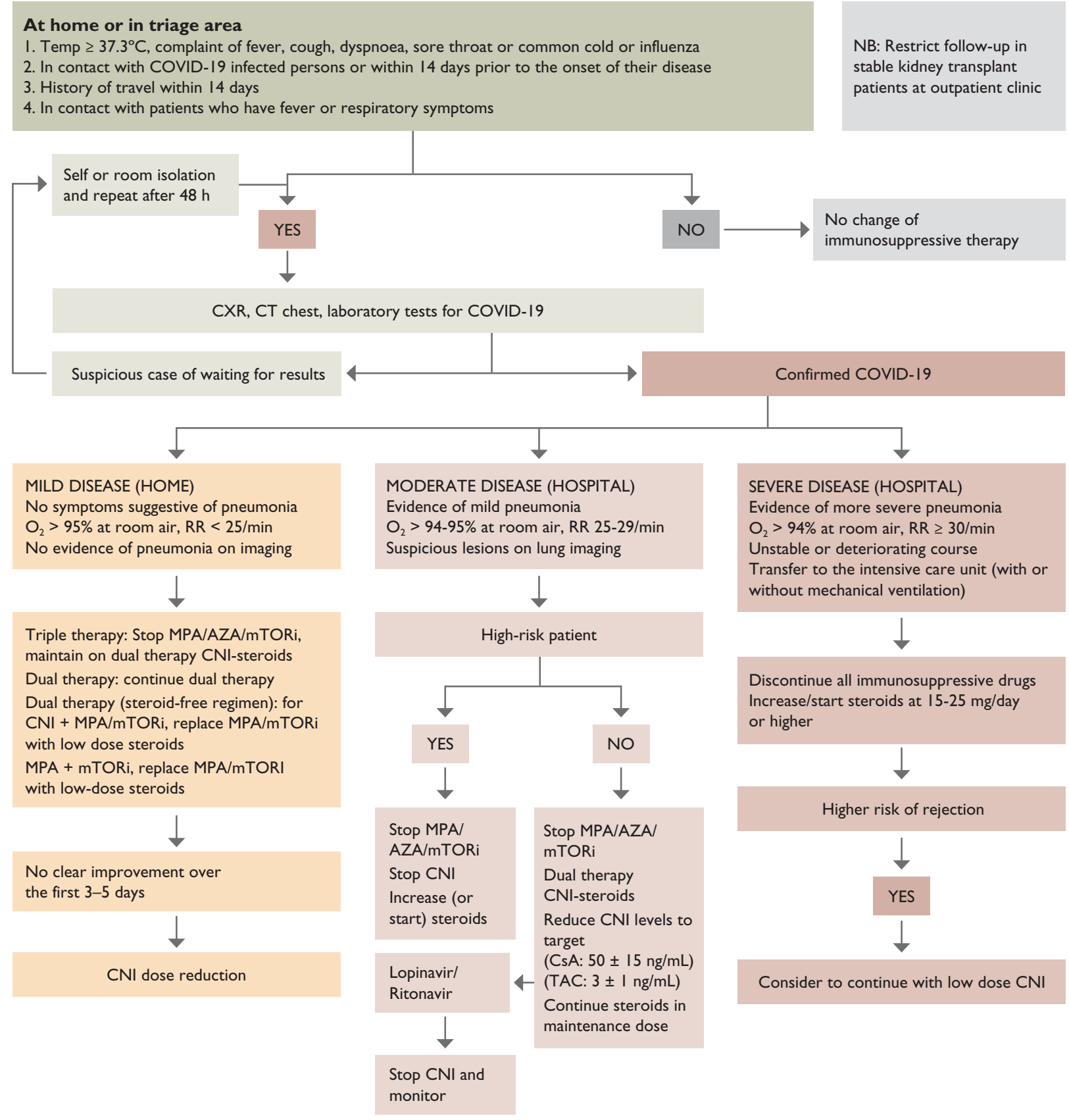

Figure 5. Proposed algorithm for the adjustment of immunosuppression in patients infected with SARS-CoV-2 (adapted from the Egyptian Ministry of Health guidelines, with permission).

Abreviations: RR, respirarory rate; $A Z A$, azathioprine; $C N I$, calcineurin inhibitor; $C s A$, cyclosporine; $m$ TORi, $m$ TOR inhibitor; MPA, mycophenolic acid; TAC, tacrolimus.

only when levels are below $50 \mathrm{ng} / \mathrm{mL}$ (overall dose reduction to one-fifth or lower, administered once a day) [62].

c. Administration of azithromycin should be accompanied with monitoring of cyclosporine levels. Azithromycin may cause increased cyclosporine concentrations through glycoprotein inhibition and/or competition for

\section{I2. CONCLUDING REMARKS}

These guidelines on COVID-19 and the kidney were commissioned by the executive committee of the African Association of Nephrology and represent a major collaborative effort by African nephrologists. They should be of practical value across the African continent and beyond. 


\section{REFERENCES}

I. World Health Organization. Coronavirus (COVID-19). 2020 https://www.afro.who.int/health-topics/coronavirus-covid-19.

2. Worldometer. Coronavirus update, I6 May 2020. https://www.worldometers.info/coronavirus/.

3. Zhang S, Diao M, Yu W, Pei L, Lin Z, Chen D. Estimation of the reproductive number of novel coronavirus (COVID-19) and the probable outbreak size on the Diamond Princess cruise ship: A data-driven analysis. Int J Infect Dis. 2020; 93:201-204.

4. Anfinrud P, Stadnytskyi V, Bax CE, Bax A. Visualizing speechgenerated oral fluid droplets with laser light scattering. N Engl J Med. 2020. DOI: I 0. I 056/NEJMc2007800.

5. Gandhi M, Yokoe DS, Havlir DV. Asymptomatic transmission, the Achilles' heel of current strategies to control Covid-19. N Engl J Med. 2020. DOI: I 0. I 056/NEJMe2009758.

6. Centres for Disease Control and Prevention. Use cloth face coverings to help slow spread. https://www.cdc.gov/coronavirus/ 20 I9-ncov/prevent-getting-sick/diy-cloth-face-coverings.html.

7. Rajgor DD, Lee MH, Archuleta S, Bagdasarian N, Quek SC. The many estimates of the COVID- 19 case fatality rate. Lancet Infect Dis. 2020. DOI: 10.1016/S1473-3099(20)30244-9.

8. Tang YW, Schmitz JE, Persing DH, Stratton CW. The laboratory diagnosis of COVID-19 Infection: current issues and challenges. J Clin Microbiol. 2020. DOI: I0.1 I 28/JCM.005 I 2-20.

9. Zhou F, Yu T, Du R, Fan G, Liu Y, Liu Z, et al. Clinical course and risk factors for mortality of adult inpatients with COVID- 19 in Wuhan, China: a retrospective cohort study. Lancet. 2020; 395( ( 0229): 1 054- 1062.

10. Wolfel R, Corman VM, Guggemos W, Seilmaier M, Zange S, Muller $M A$, et al. Virological assessment of hospitalized patients with COVID-20 19. Nature. 2020. DOI: I0. 1038/s4 I 586-020-2196-X.

I I. Cheng Y, Luo R, Wang K, Zhang M, Wang Z, Dong L, et al. Kidney disease is associated with in-hospital death of patients with COVID-19. Kidney Int. 2020; 97(5):829-838.

12. International Society of Nephrology. COVID-19 additional resources. https://www.theisn.org/covid I 9/additional-resources.

13. EDTA-ERA. COVID-19 news and information. https://www.era-edta.org/en/covid-19-news-and-information/.

14. Extance A. Covid-19 and long term conditions: what if you have cancer, diabetes, or chronic kidney disease? BMJ. 2020; 368:m I 174.

15. Li J, Li SX, Zhao LF, Kong DL, Guo ZY. Management recommendations for patients with chronic kidney disease during the novel coronavirus disease 2019 (COVID-19) epidemic. Chronic Dis Transl Med. 2020. DOI: 10.1016/j.cdtm.2020.05.00।.

16. Sriram $K$, Insel PA. Risks of ACE inhibitor and ARB usage in COVID- 19: evaluating the evidence. Clin Pharmacol Ther. 2020. DOI: $10.1002 / \mathrm{cpt} .1863$.

17. Trifiro G, Crisafulli S, Ando G, Racagni G, Drago F, Italian Society of P. Should patients receiving ACE Inhibitors or angiotensin receptor blockers be switched to other antihypertensive drugs to prevent or improve prognosis of novel coronavirus disease 2019 (COVID-19)? Drug Saf. 2020. DOI: 10.1007/s40264-020-00935-2.

18. Kronbichler A, Gauckler P, Windpessl M, II Shin J, Jha V, Rovin BH, et al. COVID-19: implications for immunosuppression in kidney disease and transplantation. Nat Rev Nephrol. 2020. DOI: I0.1038/s4 I58 I-020-0305-6.

19. Bomback AS, Canetta PA, Ahn W, Ahmad SB, Radhakrishnan J, Appel GB. How COVID- 19 has changed the management of glomerular diseases. Clin J Am Soc Nephrol. 2020. DOI: $10.2215 / \mathrm{CJN} .04530420$

20. Naicker S, Yang CW, Hwang SJ, Liu BC, Chen JH, Jha V. The novel coronavirus 2019 epidemic and kidneys. Kidney Int. 2020; 97(5):824-828.
21. George Institute for Global Health. COVID-19 additional resources. 2020. https://cdn.georgeinstitute.org/covid- 19.

22. Goverment of India, Ministry of Health \& Family Welfare. 2020. Guidelines for dialysis of COVID-19 patients. https://www.mohfw. gov.in/pdf/GuidelinesforDialysisofCovid I 9Patients.pdf.

23. George Institute for Global Health. Haemodialysis unit preparedness checklist developed to deliver safe dialysis during and after COVID-19 pandemic. 2020. https://cdn.georgeinstitute.org/sites/ default/files/covid-19-hemodialysis-unit-preparedness-checklist.pdf.

24. Centres for Disease Control and Prevention. Interim additional guidance for infection prevention and control recommendations for patients with suspected or confirmed COVID-19 in outpatient hemodialysis facilities. 2020. https://www.cdc.gov/coronavirus/2019ncov/hcp/dialysis.html.

25. Dialysis Association of South Africa. Renal dialysis facility guidelines in response to COVID-19 outbreak. 2020. http://dialysisassociation.co.za/ wp-content/uploads/2020/03/DASA-Covid-19-Guidelines-PDF.pdf.

26. Centres for Disease Control and Prevention. Using personal protective equipment (PPE). 2020. https://www.cdc.gov/ coronavirus/2019-ncov/hcp/using-ppe.html.

27. Centres for Disease Control and Prevention. operational considerations for personal protective equipment in the context of global supply shortages for coronavirus disease 2019 (COVID-19) pandemic: non-US Healthcare Settings. 2020. https://www.cdc.gov/ coronavirus/20 I 9-ncov/hcp/non-us-settings/emergencyconsiderations-ppe.html.

28. Kenya Renal Association. KRA Advisory note on the care of the renal patient in the era of COVID-19. 2020.

29. Centres for Disease Control and Prevention. Recommendation regarding the use of cloth face coverings. 2020. https://www.cdc.gov/ coronavirus/2019-ncov/prevent-getting-sick/cloth-face-cover.html.

30. National Institute of Communicable disease. COVID-19 environmental health guidelines. 2020. https://www.nicd.ac.za/ wp-content/uploads/2020/04/covid- 19-environmental-healthguideline- I-3.pdf.

31. National Institute of Communicable disease. COVID-I9 disease: infection prevention and control guidelines. 2020. https://www.nicd. ac.za/wp-content/uploads/2020/05/ipc-guidelines-covid- I 9-version2-21-may-2020.pdf.

32. World Health Organization. Guiding principles for immunization activities during the COVID-19 pandemic. 2020. https://apps.who. int/iris/bitstream/handle// 0665/33/590/WHO-2019-nCoVimmunization_services-2020. I-eng.pd?ua = I.

33. Centres for Disease Control and Prevention. Coronavirus disease 2019 (COVID-19) outpatient dialysis facility preparedness assessment tool. 2020. https://www.cdc.gov/coronavirus/2019-ncov/ downloads/COVID- 19-outpatient-dialysis. pdf?deliveryName=USCDC_425-DM26746.

34. National Institute of Communicable Disease. Guidelines for symptom monitoring and management of essential workers for COVID- 19 related infection. 2020. https:/www.nicd.ac.za/ wp-content/uploads/2020/04/Guidance-for-symptom-monitoringand-management-of-essential-staff-with-COVID-19-related-illnessfinal-2.pdf.

35. Mehta P, McAuley DF, Brown M, Sanchez E, Tattersall RS, Manson JJ, et al. COVID-19: consider cytokine storm syndromes and immunosuppression. Lancet. 2020; 395( I 0229): I 033- 1034.

36. Honore PM, Hoste E, Molnar Z, Jacobs R, Joannes-Boyau O, Malbrain $M$, et al. Cytokine removal in human septic shock: Where are we and where are we going? Ann Intensive Care. 2019; 9(1):56.

37. Ronco C, Reis T. Kidney involvement in COVID-19 and rationale for extracorporeal therapies. Nat Rev Nephrol. 2020. DOI: 10.1038/s4| 58 I-020-0284-7. 
38. Goldfarb DS, Benstein JA, Zhdanova O, Hammer E, Block CA, Caplin NJ, et al. Impending shortages of kidney replacement therapy for COVID- 19 Patients. Clin J Am Soc Nephrol. 2020. DOI: 10.2215/cjn.05 I80420.

39. International Society for Peritoneal Dialysis. ISPD: Strategies regarding COVID- 19 in PD patients. 2020. https://ispd.org/ wp-content/uploads/ISPD-PD-management-in-COVID-19_ENG.pdf.

40. British Renal Society, The Renal Association. COVID- 19: Checklist and guidance for management of peritoneal dialysis programmes. 2020. https://renal.org/wp-content/uploads/2020/04/COVIDI9-andPD-30032020-Checklist-and-Guidance.pdf.

4I. Zaki MS, Elsayed HM, El Fishawy H. Egyptian Ministry of Health. Guidelines on acute kidney injury in COVID- 19. 2020

42. Khwaja A. KDIGO clinical practice guidelines for acute kidney injury. Nephron Clin Pract. 20 12; 120(4):c179- 84.

43. Fanelli V, Fiorentino M, Cantaluppi V, Gesualdo L, Stallone G, Ronco $C$, et al. Acute kidney injury in SARS-CoV-2 infected patients. Crit Care. 2020; 24(I): 155.

44. Ali H, Daoud A, Mohamed MM, Salim SA, Yessayan L, Baharani J, et al. Survival rate in acute kidney injury superimposed COVID-19 patients: a systematic review and meta-analysis. Ren Fail. 2020; 42(I):393-397.

45. Sun J, Zhu A, Li H, Zheng K, Zhuang Z, Chen Z, et al. Isolation of infectious SARS-CoV-2 from urine of a COVID-19 patient. Emerg Microbes Infect. 2020; 9(I):991-993.

46. Guan WJ, Zhong NS. Clinical characteristics of Covid- 19 in China. Reply. N Engl J Med. 2020; 382(19): | 86 | - 862.

47. Ronco C, Reis T, Husain-Syed F. Management of acute kidney injury in patients with COVID-19. Lancet Respir Med. DOI: 10.1016/S2213-2600(20)30229-0.

48. Richardson S, Hirsch JS, Narasimhan M, Crawford JM, McGinn T, Davidson KW, et al. Presenting characteristics, comorbidities, and outcomes among 5700 patients hospitalized with COVID- 19 in the New York City area. JAMA. 2020. DOI: I0.100 I/jama.2020.6775.

49. Pranskunas A, Koopmans M, Koetsier PM, Pilvinis V, Boerma EC. Microcirculatory blood flow as a tool to select ICU patients eligible for fluid therapy. Intensive Care Med. 2013; 39(4):612-619.

50. Harrois A, Grillot N, Figueiredo S, Duranteau J. Acute kidney injury is associated with a decrease in cortical renal perfusion during septic shock. Crit Care. 2018; 22(1):161.

5I. Levy MM, Evans LE, Rhodes A. The Surviving Sepsis Campaign Bundle: 2018 update. Crit Care Med. 20 I8; 46(6):997-I000.

52. Salahuddin N, Sammani M, Hamdan A, Joseph M, Al-Nemary Y, Alquaiz R, et al. Fluid overload is an independent risk factor for acute kidney injury in critically III patients: results of a cohort study. BMC Nephrol. 2017; 18(1):45.

53. Bellomo R, Ronco C, Mehta RL, Asfar P, Boisrame-Helms J, Darmon $M$, et al. Acute kidney injury in the ICU: from injury to recovery: reports from the 5 th Paris International Conference. Ann Intensive Care. 2017; 7(1):49.

54. Martin GS, Bassett P. Crystalloids vs. colloids for fluid resuscitation in the Intensive Care Unit: A systematic review and meta-analysis. J Crit Care. 20 19; 50: I 44-I54.

55. Caironi P, Tognoni G, Gattinoni L. Albumin replacement in severe sepsis or septic shock. N Engl J Med. 2014; 370: 1412-1421.

56. El Shamy O, Sharma S, Winston J, Uribarri J. Peritoneal dialysis during the coronavirus 2019 (COVID-19) pandemic: acute inpatient and maintenance outpatient experiences. Kidney Med. 2020. DOI: 10.1016/j.xkme.2020.04.001.

57. American Society of Nephrology. Recommendations on the care of hospitalized patients with COVID- 19 and kidney failure requiring renal replacement therapy. 2020. https://www.asn-online.org/g/blast/ files/AKI_COVID-19_Recommendations_Document_03.21.2020.pdf.
58. Nieuwenhuijs-Moeke GJ, Sanders JSF. Timing of renal replacement therapy in acute kidney injury: case closed? Lancet. 2020; 395( ( 0235): | 465- I 467.

59. British Renal Society. Acute peritoneal dialysis on intensive care units protocol. 2020. https://vo2k0qci4747qecahf07gktt-wpengine. netdnassl.com/wp-content/uploads/2020/04/Acute-Peritoneal-Dialysis-onIntensive-Care-Units-protocol.pdf.

60. Song JC, Wang G, Zhang W, Zhang Y, Li WQ, Zhou Z, et al. Chinese expert consensus on diagnosis and treatment of coagulation dysfunction in COVID-19. Mil Med Res. 2020; 7(1):19.

61. Xiong M, Liang X, Wei YD. Changes in blood coagulation in patients with severe coronavirus disease 2019 (COVID-19): a meta-analysis. Br J Haematol. 2020. DOI: 10.1 I I //bjh. 16725.

62. University of Liverpool. COVID-19 drug interactions. 2020. https://www.covid I9-druginteractions.org/.

63. Zaki MS, Elsayed HM, El Fishawy H. Egyptian Ministry of Health. Guidelines on kidney transplant and COVID-19. 2020.

64. Akalin E, Azzi Y, Bartash R, Seethamraju H, Parides M, Hemmige V, et al. Covid-19 and kidney transplantation. N Engl J Med. 2020. DOI: 10.1056/NEJMc20IIII7.

65. Coates PT, Wong G, Drueke T, Rovin B, Ronco P. Early experience with COVID- 19 in kidney transplantation. Kidney Int. 2020. DOI: 10.10 16/j.kint.2020.04.001.

66. Gandolfini I, Delsante M, Fiaccadori E, Zaza G, Manenti L, Degli Antoni A, et al. COVID-19 in kidney transplant recipients. Am J Transplant. 2020. DOI: I0.1 I | |/ajt. I589 I.

67. Banerjee D, Popoola J, Shah S, Ster IC, Quan V, Phanish M. COVID- 19 infection in kidney transplant recipients. Kidney Int. 2020. DOI: 10.1016/j.kint.2020.03.018.

68. Johnson KM, Belfer JJ, Peterson GR, Boelkins MR, Dumkow LE. Managing COVID- 19 in renal transplant recipients: a review of recent literature and case supporting corticosteroid-sparing Immunosuppression. Pharmacotherapy. 2020. DOI: 10.1002/phar.24I0.

69. Wang J, Li X, Cao G, Wu X, Wang Z, Yan T. COVID-19 in a kidney transplant patient. Eur Urol. 2020. DOI: 10.1016/j. eururo.2020.03.036.

70. Gori A, Dondossola D, Antonelli B, Mangioni D, Alagna L, Reggiani P, et al. Coronavirus disease 2019 and transplantation: A view from the inside. Am J Transplant. 2020. DOI: 10.1 I I l/ajt. 15853.

71. American Society of Transplantation. COVID-19 Information. 2020. https://www.myast.org/covid-19-information.

72. ERA-EDTA. ERA-EDTA 2nd COVID-19 Q\&A Webinar. 2020. https://m.youtube.com/watch?v=HLuljXAyu6A. 